\title{
A Study to Determine the Ability of Fifth-grade Students in Reflecting their Knowledge about Sun, Earth, and Moon by Different Measurement Tools
}

\author{
Salih Gülen* \\ Department of Child Development, University of Muş Alparslan, Muş, Turkey \\ *Corresponding Author: sgnova@windowslive.com
}

\section{ABSTRACT}

The aim of this study was to determine the knowledge of fifth-grade students about the sun, earth, and moon and to examine the fact that this information can be reflected with different measurement tools. A mixed method was used in the research. Quantitative data were collected using a 3-point Likert-type questionnaire and a true-false test; and qualitative data were collected through a fully structured interview and a three-dimensional thinking skills form. It was determined that students knew about the sun, earth, moon, and their properties. However, the students could not provide any data about the distances between the sun, earth, and moon. When the pictures of the students were examined; while very high data were presented for the size and distance related to the sun, earth, and moon, very low data were found for the rotation relationship. The information obtained from the fully structured interview form was determined to reflect the information obtained from the three-dimensional thinking form at a medium level. In addition, according to survey data, the students have a very good level of knowledge and they reflected this information to a good level in the true-false test. To measure the students' level of knowledge, a survey or true-false tests could be used. As a matter of fact, they both offer the same results.

KEY WORDS: astronomy; knowledge; three dimensions; reflection

\section{INTRODUCTION}

$\circlearrowleft$ i cience is a discipline that requires sensitivity in teaching in terms of the subjects and concepts. Particular effort is required in teaching concepts which are difficult (i.e., astronomy). As a matter of fact, many studies in science education focus on concept education (for example, Lin et al., 2018). In the teaching of concepts in this style, it is aimed to use activities such as painting, modeling, animation, and simulation to gain a place in the mental structure of students (Kiroğlu et al., 2019). Therefore, it is known that students can use methods such as drawing when specifying concepts in their mental structure.

Drawing has been seen as a way of expressing the emotions of people and as a means of communication since ancient times (Şahin, 2014). Especially for the imaginary, inaccessible, or distant (such as the sun), concepts or objects are weighted (earth). Thanks to drawing, students' three-dimensional thinking ability is able to be developed (Diğler, 2018; Yenilmez and Şan, 2008). Three-dimensional thinking is generally thought of as the visible sides of a concept or object, as well as its invisible sides. It is thought that the students are able to learn about the sun, earth, and moon thanks to their three-dimensional thinking abilities. It has been reported that students are usually able to express themselves by drawing pictures (Çakmak et al., 2014; Kahraman, 2018). Therefore, students should be able to draw a picture to express what they have learned about sun, earth, and moon. The important point here is students able to pay attention to basic points of these celestial bodies. In the drawings that the students make about a spatial object, it is necessary to design the object in the mind with three dimensions in space and put it into the drawing (Olkun and Altun, 2003). The relationship between size, distance, and rotation between them are the points to be considered in the pictures.

The Ministry of Education (MoNE) (2018) has explicitly indicated content to be included in Turkish science textbooks as well as topics to be covered in classrooms. These topics include the properties of the sun, the movement of the sun, the properties of the moon, the phases of the moon, the sun, earth, and the moon's rotation, as well as the ability to create a model of the sun, earth, and moon. Especially, information about the sun, earth, and moon are taught in line with the existing opportunities (school facilities, planetarium in the region, such as models to be used by the teacher) (Bozdemir et al., 2017). However, as all these events occur in threedimensional space, they require three-dimensional thinking (Kiroğlu et al., 2019). As a result, the learning environment should be designed accordingly (Gülen and Demirkuş, 2014). Planetarium, science museums, practice centers, excursions, and exhibitions have been shown to be more effective for these subjects and concepts (Falk and Dierking, 2018; Türk and Kalkan, 2018). The assessment and evaluation activities carried 
out in education are aimed at determining the students' ability to use the information they have learned and to adapt them to different situations (Ary et al., 2019). In addition, the student's work is expected to reflect the information contained in the measurement tool or tools (Özer, 2018). As a matter of fact, the measurement tool should have been designed to test whether or not the target information has been acquired (Kırınd 1 and Ulu, 2017). Researchers, especially in the study of astronomy have identified that individuals often have misconceptions or use alternative concepts (Bektaşl1, 2013). One reason for these misconceptions is that the student thinks he/she has learned the information but cannot apply it to different situations. It is important that the student is able to reflect on the information learned. In this study, reflection refers to the student's ability to communicate. Reflection is the thinking we have to develop concepts and ideas by focusing on our actions (Adatepe, 2018). It is the process of thinking to reveal the positive or negative aspects of the subjects learned and to solve problems (Ersozlu and Kazu, 2011; Kızılkaya and Askar, 2009). In addition, it can be argued that students construct knowledge in a conscious way away from random thoughts. Reflection of the content learned here is related to the learning experience (Elald 1 and Semerci, 2018). In fact, students should be expected to reflect on a subject or concept that has been fully learned in another context (Bozkurt and Özdemir, 2018).

Research shows that students' information about the sun, the earth, and the moon is generally at the level of basic fact knowledge (Deniş and Balım, 2012; Gülen and Demirkuş, 2014; Üstün and Eryılmaz, 2014). It can be said that students generally learn this information from their science books, teachers, or elder family members (Gülen, 2019). In fact, what is important here is the level of knowledge learned. Does the student know how to adapt his/her knowledge to different situations? In other words, does it reflect the answers from one measurement tool to another measurement tool? Ideally, similar results should be obtained with different measurement tools. In this study, do a student's knowledge about the sun, the earth, and the moon show the same results indifferent measuring tolls? Do students reflect their knowledge about the sun, earth, and moon in three-dimensional images or drawings? The answers to these questions are important for research. The answers to these questions were questioned within the scope of this paper's research.

\section{Purpose of the Research}

The main aim of this study was to determine the knowledge of fifth-grade students about the sun, earth, and moon and to examine if this information can be reflected in indifferent measurement tools. For this purpose, the answers to the following questions were sought:

1. What is the knowledge of students about the sun, the earth, and the moon?

2. Do students reflect the three-dimensional information about the sun, earth, and moon in their paintings?

3. What is the rate of reflection of the knowledge levels determined by the survey data to the true-false test?
4. Is there a significant difference in the knowledge of the students about the sun, earth, and moon according to two different scales?

\section{METHODOLOGY}

A mixed method was used in this research. Both qualitative and quantitative data are aimed at closing the deficiencies in the solution of research problems. Qualitative data were collected together with quantitative data (Büyüköztürk, 2009; Creswell, 2013; Çepni, 2010). The following steps were followed in the research, Table 1.

Table 1 shows the steps and provides an explanation of the process followed in this study.

\section{Participants}

Similar population samples were used in the study. The aim of the analogous sample is to determine the status of groups with similar characteristics to collect the data effectively (Yıldırım and Şimşek, 2013). The research was conducted with fifth-grade students in a public school in the Eastern Anatolia Region during the 2018-2019 academic years. Permission was obtained from the school administration for the study. The participants volunteered to participate in the study. A total of 135 students participated in the study. The socio-economic status of the participants was similar. In addition, at the start of the 2018-2019 academic years, the participants learned the characteristics of the sun, earth, and moon, and the movements of the trio. It was determined that the students prepared a model of the sun, earth, and moon as part of their learning. In these models, the movements and relationships of celestial bodies are represented. They also discussed their life on earth and on other planets. The students experienced these topics in the classroom environment under the guidance of a teacher. The teacher did not use any model or computer simulation in the presentation of these subjects.

\section{Data Collection Tools}

A 3-point Likert-type questionnaire (Appendix 1) and true-false test (Appendix 2) were used to collect quantitative data. Qualitative data were collected through a fully structured interview form (Appendix 3), and a three-dimensional thinking ability (drawing) (Appendix 4).

\section{Analysis of Data}

The data from the study's measurement were analyzed with the help of the SPSS program (version 17), Lisrell, and Microsoft Excel programs. In addition to descriptive and content analysis, techniques such as T-test, Z-score, frequency, percentage, factor analysis, and Cronbach's alpha reliability were used.

The data of the fully structured interview form were analyzed both descriptively and in content to determine the information (thinking) related to the sun, earth, and moon. The data obtained by both analysis methods are presented in the findings section. The three-dimensional thinking form (drawing) is analyzed in light of the criteria mentioned in Table 2. 


\begin{tabular}{lll}
\hline \multicolumn{2}{l}{ Table 1: Steps followed in the research } & \\
\hline Order & Steps & Description \\
\hline A & Topic & The subject was determined according to the purpose of the research \\
B & Examination & The course program and book have been examined \\
C & Measuring tools & The tools used to find the answers to the research questions were selected \\
D & Application & 1. Time to think: It is prepared to determine the thoughts of the students about the subject \\
& & 2. Picture time: Used to measure students' thoughts \\
& Analysis & 3. Time to test: It was used to determine the students' configuration status of the cases \\
E & Results & Data obtained from measurement tools were analyzed \\
F & & The findings were determined and presented \\
\hline
\end{tabular}

Table 2 presents the evaluation criteria for three-dimensional thinking skills form data. It is assumed that the data containing these criteria cover the size corresponding to the data. One data may contain more than one size, or may not contain any of them. Likert test was scored as disagree (1 point), undecided ( 2 points), and agree ( 3 points). The averages of these scores were interpreted according to Table 3. Each true-false test items were evaluated as five points according to the percentage distribution. There were 20 items in the test. Since 100/20 $=5$, the student received five points for each correct. The scores of the survey and the true-false tests were standardized and interpreted by comparing them with the $\mathrm{Z}$ score. In addition, the criteria of Table 3 were complied with in interpreting the frequency values obtained according to percentage ratios.

The mean scores of the participants in the survey were taken. In addition, the criteria in Table 3 were taken into consideration in the interpretation of the survey data.

As shown in Table 3, five equal intervals were determined for more precise interpretation. According to this, it is very bad, bad, middle, good, and very good value for survey and three-dimensional.

For the coding and scoring, the reliability was calculated using the formula of Miles and Huberman (1994). According to this calculation, $90 \%$ confidence coding was performed throughout the study. According to Miles and Huberman (1994), 80\% and above are accepted as reliable (Arık and Yılmaz, 2017).

\section{Reliability and Validity}

Within the scope of the reliability studies, the status of the sample group was explained in detail, the existing roles were explained, and the conceptual framework and data collection and analysis were presented. In addition, these data were supported by descriptive analysis and content analysis (Glesne, 2013). The fully structured interview form used and the three-dimensional thinking form (drawing) were prepared by consulting an expert. The analysis received help from their teachers. In addition, Cronbach's alpha value of the survey tool was 0.83 and Cronbach's alpha value of the true-false test was calculated as 0.71 . Finally, the exploratory factor analysis of the questionnaire was conducted. The explanatory factor analysis values are given below.

As shown in Table 4, the Kaiser-Meyer-Olkin values of scales are above the acceptable value. Bartlett's test of sphericity test

\begin{tabular}{|c|c|c|c|c|}
\hline S. No. & Criteria & Size & Distance & Rotation \\
\hline 1. & $\begin{array}{l}\text { If there is a size ratio between sun, } \\
\text { earth, and moon }\end{array}$ & Yes & & \\
\hline 2. & If the drawing is bad but the size ratio & Yes & & \\
\hline 3. & $\begin{array}{l}\text { Size is not very good, but the } \\
\text { distance is proportional }\end{array}$ & & Yes & \\
\hline 4. & $\begin{array}{l}\text { If there is a distance ratio in the } \\
\text { drawings }\end{array}$ & & Yes & \\
\hline 5. & $\begin{array}{l}\text { Sun, earth, and moon orbits are } \\
\text { specified }\end{array}$ & & & Yes \\
\hline 6. & $\begin{array}{l}\text { If there is a direction of rotation } \\
\text { between sun, earth, and moon }\end{array}$ & & & Yes \\
\hline
\end{tabular}

\begin{tabular}{llcc}
\hline \multicolumn{3}{l}{ Table 3: Interpretation value of scores } \\
\hline Order & Value & $\begin{array}{c}\text { Range for } \\
\text { survey }\end{array}$ & $\begin{array}{c}\text { Range for three- } \\
\text { dimensional (\%) }\end{array}$ \\
\hline 1 & Very bad & $0.00-0.59$ & $00.01-20$ \\
2 & Bad & $0.60-1.19$ & $20.01-40$ \\
3 & Middle & $1.20-1.80$ & $40.01-60$ \\
4 & Good & $1.81-2.40$ & $60.01-80$ \\
5 & Very good & $2.41-3.00$ & $80.01-100$ \\
\hline
\end{tabular}

\begin{tabular}{lccc}
\hline \multicolumn{3}{l}{ Table 4: Calculated values of exploratory factor analysis } \\
\hline Variables & Acceptable value & Survey & Factor \\
\hline Kaiser-Meyer-Olkin & $\geq 0.50$ & 0.82 & Doable \\
Bartlett's test of sphericity & $\geq \mathrm{n}$ & 594.075 & Doable \\
$\rho$ & $\leq 0.05$ & 0.000 & Doable \\
\hline
\end{tabular}

values shows high jump values depending on the number of participants. Finally, " $\rho$ " significance indicates that the data were meaningful (Field, 2000). The values in Table 4 show that this scale can be taken to confirm factor analysis.

In the descriptive and content analysis of the validity of the research, direct quotations were given, and the accuracy of the research results is shown (Merriam, 2013). The codes used in the content analysis and the interpretations were done in depth. In addition, subject gains were taken into consideration for the scope validity of the true-false test. Validity values such as structure and appearance are obtained 
by taking an expert's opinion (Yıldırım and Şimşek, 2013). The validity values of the validation factor of the survey tool are presented below.

When Table 5 is examined, it can be seen that the majority of the values of the results of the implementation are not of an acceptable value, but close to the acceptable value. The scale's pattern charts and all other data values can be used because of the acceptance of these values (Schermelleh-Engel et al., 2003). Based on these data, the pattern charts of the scales are given below.

\section{RESULTS OF RESEARCH}

The data obtained from the analysis of the measurement data used in the research are presented below. The description of the data obtained in the fully structured interview form analysis is shown in Table 6.

One hundred and thirty-five students participated in the structured interview form. However, five students' papers were not evaluated, as they did not reply to the full structured interview form. As shown in Table 6, the most frequently repeated three statements have a ratio of $60 \%$ with a frequency of 78 to "The Sun gives the Earth heat and light." "The Moon revolves around the Earth" has a ratio of $50.77 \%$ with 66 frequencies. Finally, "The Earth revolves around the Sun" has a ratio of $63.4 \%-48.46 \%$. As it can be seen in the table, students' expressions about the sun, earth, and moon are generally understood to be related to the physical properties and the relationship between them. In addition, the content analysis is presented below.

As a result of analyzing the data of the fully structured interview form, the following quotations are presented under the themes "General Features of Sun, Earth, and Moon" and "The Relationship between the Sun, Earth, and Moon."

\section{General Features of Sun, Earth, and Moon}

Under this theme, the codes were determined according to the characteristics of these three celestial bodies and presented below with the categories:

\section{Sun}

In this category, the quotations of the participants according to the sun and its features are as follows. The quotations were randomly selected among the participants:

The Sun is a star. It is very hot (P1).

The Sun is a star in the Milky Way galaxy. Solar heat and light source. There are larger stars in the sun (P26).

Sun consists of layers. It is larger than Earth and Moon. The shape is like a sphere.... It is a medium-sized star. The sun gives us heat and light (P57).

Solar heat and light source. It is a medium-sized star. It consists of layers. It revolves around itself. Around the Milky Way galaxy. There are stains on it. These are called sunspots. Large explosions occur on the surface (P83).
Table 5: Compliance indexes calculated by confirmatory factor analysis

\begin{tabular}{lcc}
\hline Compliance indexes & Acceptable value & Survey \\
\hline Chi-square/degree of freedom & $\leq 3.00$ & 0.98 \\
GFI & $\geq 0.90$ & 0.95 \\
AGFI & $\geq 0.80$ & 0.94 \\
CFI & $\geq 0.90$ & 0.97 \\
RMSEA & $\leq 0.06$ & 0.01 \\
\hline
\end{tabular}

GFI: Goodness-of-fit index, AGFI: Adjusted goodness-of-fit index, NNFI: Non-normed fit index, CFI: Comparative fit index, RMSR: Root mean square residual, RMSEA: Root mean square error of approximation

\begin{tabular}{|c|c|c|c|}
\hline Order & $\begin{array}{l}\text { Most repetitive expressions } \\
\text { (n: 130) }\end{array}$ & Frequency (f) & Percent \\
\hline 1 & The sun gives the earth heat and light & 78 & 60.00 \\
\hline 2 & The moon revolves around the earth & 66 & 50.77 \\
\hline 3 & Earth revolves around the sun & 63 & 48.46 \\
\hline 4 & The earth is where we live & 58 & 44.62 \\
\hline 5 & Moon revolves around itself & 56 & 43.08 \\
\hline 6 & Earth revolves around itself & 56 & 43.08 \\
\hline 7 & The moon revolves around the sun & 55 & 42.31 \\
\hline 8 & Sun is a star & 50 & 38.46 \\
\hline 9 & Sun revolves around itself & 46 & 35.38 \\
\hline 10 & $\begin{array}{l}\text { The sun turns/wanders in the milky } \\
\text { way galaxy }\end{array}$ & 38 & 29.23 \\
\hline 11 & The moon has phases & 36 & 27.69 \\
\hline 12 & The moon is earth's satellite & 30 & 23.08 \\
\hline 13 & The sun is bigger than earth & 30 & 23.08 \\
\hline 14 & $\begin{array}{l}\text { The moon reflects the light it } \\
\text { receives from the sun }\end{array}$ & 27 & 20.77 \\
\hline 15 & Earth is larger than the moon & 21 & 16.15 \\
\hline 16 & There are craters on the moon & 19 & 14.62 \\
\hline 17 & $\begin{array}{l}\text { The sun, earth, and moon are } \\
\text { spherical }\end{array}$ & 18 & 13.85 \\
\hline 18 & The sun is larger than the moon & 17 & 13.08 \\
\hline
\end{tabular}

The sun stays in place. As the world turns, it also gives warmth. The Sun in the mornings of the Earth (P119).

As it is understood from the above quotations, it was stated by the participants that the Sun was a "medium-sized star," that it gave us "heat and light," that the shape was "spherical," and "larger" than the earth and the moon. It is also stated that the Sun is in the "Milky Way" galaxy and it makes a "rotational movement." According to these data, it is possible to say that the participants have some knowledge about the sun and know its features.

\section{Earth}

In this category, participants were informed about the earth. Representative quotations randomly selected to represent the participants' responses are:

Earth, we live in (P19).

There are people, cities, clouds, industries, and villages around the world (P33). 
The Earth rotates and is spherical in shape. It's a planet. It's where we live (P86).

It is the only planet in which life exists. It is spherical. Bigger than the Moon, smaller than the Sun. Earth revolves around itself, wandering around the sun. Earth's natural satellite is Moon (P96).

The shape of the Earth is geoids. The world revolves around itself and the Sun. The rotation time of the sun is 365 days $6 \mathrm{~h}$ (1 year) (P117).

The above quotations indicate that the participants stated that the "planet" where we "live," where there are "living things" and "people" is the Earth. It is stated that the Earth "revolves" around itself and the "Sun" and the Moon is a "satellite" that revolves "around" the earth. It is also stated that the "shape" of the Earth is "spherical/geoids." Finally, it is stated that the Earth's rotation "time" around the Sun is "365 days $6 \mathrm{~h}$ (1 year)." According to these data, it is possible to say that the participants have knowledge about the earth and know its features.

\section{Moon}

Under this category, the participants' statements about the moon were analyzed. Randomly selected citations:

There are main and intermediate phases. Turns around the Earth. With the Earth revolves around the Sun (P12).

Moon is not a light source. It reflects the light it receives from the Sun to the Earth (P44).

Pits occur as a result of meteor impact. The name of these pits is the crater. Moon is the Earth's only satellite (P74).

There is no atmosphere in the Moon. There are main and intermediate phases of the Moon (P89).

The Moon returns around 27 days and 8 h on its own (P118).

It is understood that the participants stated that the Moon is a "satellite" with "craters" on its surface. In addition, it is determined that the "return" period of the Moon is "27 days and $8 h$ " and they know that Moon turns "with the Earth" around the Sun. In general, it is also possible to say that the participants have some knowledge about the moon.

In the analysis made with the categories of sun, earth, and moon under the theme of general features of sun, earth, and moon, it can be said that the participants know these celestial bodies at a sufficient level. In addition, the determination of the relationship between these celestial bodies is important for research. Accordingly, under the following theme, the participants' expressions about the relationship between sun, earth, and moon were analyzed.

\section{The relationship between sun, earth, and moon}

Under this theme, quotes describing the relationship between the sun, earth, and moon were analyzed under the following categories.
Size - In this category, the sun, earth, and moon were examined with respect to each state's size. The quotations of the participants are presented below (randomly selected):

The Sun is larger than the Earth and Moon. The smallest is the Moon. The largest of the Sun is the Middle of the star (P6).

The Sun is a. watermelon, The Earth is a Mandarin and the Moon is the size of a chickpea (P35).

The Sun, Earth, and Moon are both in space and spherical. The largest is the Sun, the Median is the Earth, and Moon is the smallest. The Sun similar to basketball ball, Earth is similar to football and the Moon is similar to the tennis ball (P96).

The sun is so big. The sun is far greater than the Earth. The Earth is large, but smaller than the Sun. The Moon is very small. It is too small from the Earth and Sun (P120).

As is understood from the quotations, it is understood that the participants stated that the sun is "bigger" than the earth and the moon and that the "youngest" is the moon. Various "analogies" were also made. The most obvious analogy is that the sun is as big as a "watermelon," the earth as a "mandarin" and the moon as a "chickpea." From these data, it can be said that the participants were informed about the order of the magnitude and size of the sun, earth, and moon.

Distance - There was only one statement provided under this category:

There are 300 million $\mathrm{km}$ between the Sun and Earth (P64).

In the above excerpt, it is stated that the distance between the sun and the earth is "300 million $\mathrm{km}$." Although the stated distance is twice the reality, it can be said that the participant was able to draw attention to the distance between the sun and the earth. In general, it can be said that most participants did not provide any data for the distance between the sun, earth, and moon.

Rotation - The citations of the participants about the rotational movements of the sun, earth, and moon in relation to each other and their location in the universe are presented below (randomly taken):

The Sun revolves around itself and in the Milky Way galaxy. The Earth revolves around itself and the Sun. The Moon revolves around the Earth and the Sun itself (P2).

They all have a certain trajectory. They follow each other (P5).

They all turn around each other and are like conjoined brothers. One warms people, the other lived people, and the other in the evening (P38).

The Earth revolves around the Sun with the Moon, which creates 1 year (365 days $6 \mathrm{~h}$ ). The Earth revolves around itself in 1 day (24 h) (P61).

The Sun sweeps through the Milky Way galaxy, and it revolves around itself. The Moon wanders around the world. It 
wanders around the Sun and it revolves around itself. Earth around itself $24 \mathrm{~h}$ a day, and return around the Sun 365 days 6 h (1 year) (P83).

The Sun, Earth, and Moon turn from west to east (P125).

The above quotations indicate that the participants had the knowledge that the sun had "returned" both "its own" and the "Milky Way" galaxy. It is also stated that the earth "revolves" around "itself" $24 \mathrm{~h}$ "a day" and revolves "around" the sun "with" the moon in "365 days, 6 h or 1 year." It is also understood that these three are like "brothers" and think they exist for "humans." Finally, it was stated that the sun, earth, and moon were turning from "west to east." According to these data, it can be said that the participants have a sufficient level of knowledge about the relation between the sun, earth, and moon. In general, according to the participants' structured interview form data, it is understood that the participants know the characteristics of the rotation of sun, earth, and moon.

The data in Table 7 were evaluated by two different raters. The consistency of the given scores was determined by $93 \%$ (Miles and Huberman, 1994). As shown in Table 5, the participants in the drawings related to the sun, earth, and moon the size of 99 (f) of $79.44 \%$, the distance of 122 (f) to $91.73 \%$ and it is understood that the direction of rotation of 12 (f), that is, $9.02 \%$. In addition, the number of participants indicating three dimensions together was determined to be 12 (f), which is $9.02 \%$.

As shown in Figures 1-3, it was determined that the students reflected their knowledge about sun, earth, and moon in their drawings. In Table 8, survey and true-false test statistics are given.

As shown in Table 8, the mean score of the questionnaire was 2.50 according to the criteria range determined this value is interpreted as very good. In addition, $12.61 \times 5=63.05$ mean score of the data obtained from true-false test is obtained. The independent groups' t-test results are given below when a significant difference is observed between the scores obtained from both scales.

Table 9 shows whether there is a significant relationship between the scores obtained from the questionnaire and the true-false tests. Accordingly, Table 9 indicates " $\rho$ " value $>0.05$ indicating that there is no significant difference between the test scores.

Table 7: Three-dimensional thinking ability form statistical values

\begin{tabular}{llccl}
\hline $\begin{array}{l}\text { Subject } \\
\text { (n: 133) }\end{array}$ & Dimensions & $\begin{array}{c}\text { Frequency } \\
\text { (f) }\end{array}$ & Percentage & Comment \\
\hline Sun, earth, & Size & 99 & 79.44 & High \\
and moon & Distance & 122 & 91.73 & Very high \\
& Rotation & 12 & 9.02 & Very low \\
& $\begin{array}{l}\text { Three- } \\
\text { dimensional }\end{array}$ & 12 & 9.02 & Very low \\
& & & & \\
\hline
\end{tabular}

\section{DISCUSSION}

According to the findings of the fully structured interview form, the students knew about the sun, earth, and the moon and their properties. It was determined that the students were informed about their respective magnitude and size ratios. Furthermore, it can be said that the students had a sufficient level of knowledge about the relationships between the sun, earth, and moon. However, it was determined that the students did not provide any data for the distance between the trio. This may be because the students refrained from presenting numerical data or because they did not know the correct figures as the reason for not presenting data on this subject. In fact,

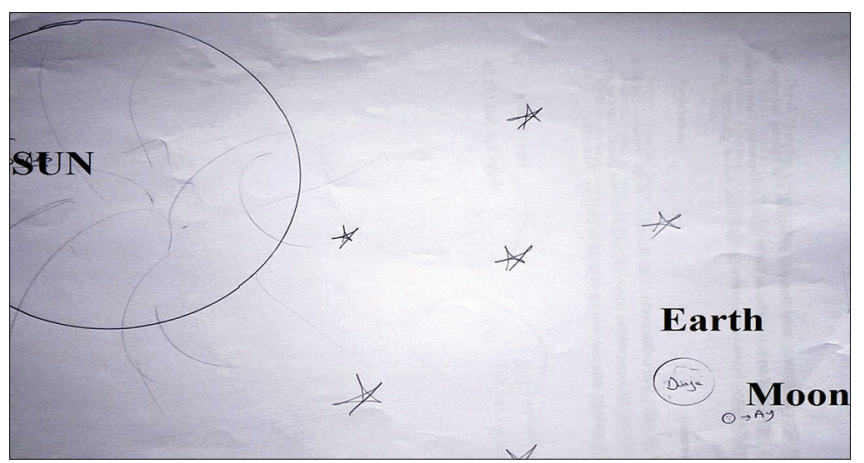

Figure 1: Example of a student' drawing 1

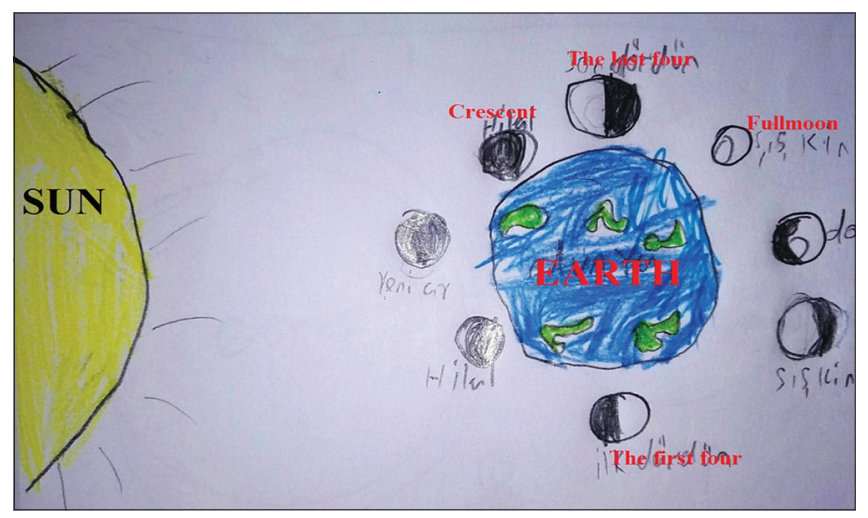

Figure 2: Example of a student's drawing 2

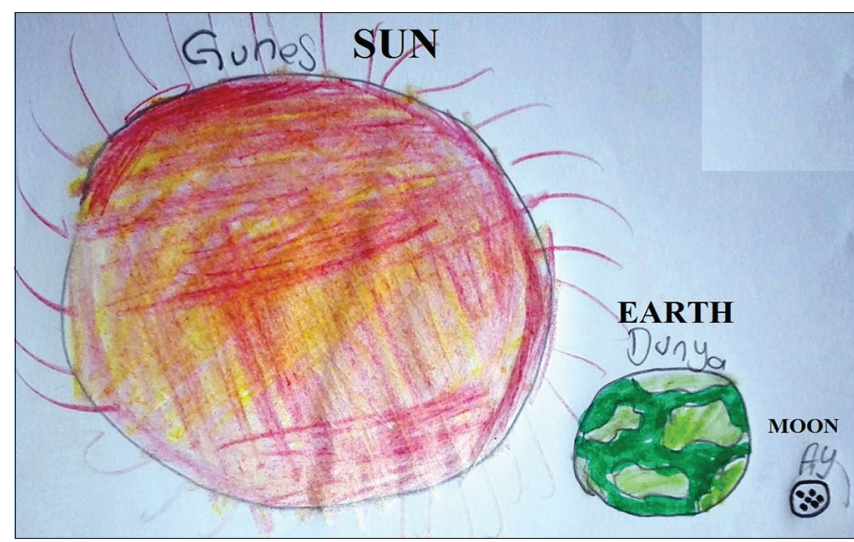

Figure 3: Example of student's drawing 3 


$\begin{aligned} & \text { Table 8: Analysis of the scores obtained from the survey } \\
& \text { and true-false tests }\end{aligned}$
\begin{tabular}{lcc} 
Scales ( $\mathrm{n}:$ 135) & Average & Z points \\
\hline Survey test & 2.50 & 0.68 \\
True-false test & 12.61 & 0.83 \\
\hline
\end{tabular}

\begin{tabular}{|c|c|c|c|c|c|c|c|}
\hline Scales scores & $\mathrm{n}$ & Mean & SD & SEM & $\mathbf{T}$ & SD & $\rho$ \\
\hline Survey test & 132 & 0.68 & 0.73 & 0.064 & -1.897 & 262 & 0.059 \\
\hline True-false test & 132 & 0.83 & 0.55 & 0.048 & & & \\
\hline
\end{tabular}

various simulation and computer programs or models should be used in the presentation of such concepts and features. It has been reported that these kinds of materials make it easier for students to learn this information (Kurnaz et al., 2016). Similarly, Kiroğlu et al. (2019) reported that three-dimensional models and computer simulations conveyed similar amounts of information, but that the three-dimensional models were more influential in supporting students' learning. Similarly, Aydın (2013) stated that students learned astronomy concepts better with virtual modeling.

According to the findings of the form used to measure three-dimensional thinking, it was understood that the students indicated a high level of knowledge about the size between the sun, earth, and moon, and a very high level of information about the distance. However, it was determined that the students had a very low relationship between the rotation of them and the data for all three dimensions. It is thought that students did not transfer data due to problems in the drawing. In addition, according to Türk and Kalkan (2017), these concepts are mentioned in a three-dimensional universe and that students should imagine them in such an environment. Similarly, Trundle et al. (2007) in their study as a result of observational experiments based on students' astronomy concepts in the drawings received positive results. Finally, Demiralp (2006) and Şahin (2014) stated that visual stimuli for objects affect the affective aspects of the child. Based on these, it is likely that there will be deficiencies in relation to the sun, earth, and moon in the drawings and the whole of the three dimensions. This is because students learn the concepts of these objects only from their teachers and textbooks.

From the findings of the fully structured interview form, it can be said that the proportions between the sun, earth, and the moon reflect the three-dimensional thinking form. However, it is understood that the students did not reflect the rotation relationship between sun, earth, and moon in three-dimensional thinking, which was one of the findings from the fully structured interview form. Similarly, Trumper (2010) stated that students may have difficulty presenting information indifferent forms. Perhaps they could have been more comfortable in their drawings if they learned these concepts in the computer environment or through models. Olkun and Altun (2003) found that students studying images on spatial objects in the computer environment were more successful in drawing. Apart from these, it can be said that the students did not use the expressions of the distance between sun, earth, and moon in the fully structured interview, but they paid attention to the distance in the form, which determines the three-dimensional thinking. Here, it is understood that the students did not present the expressions in the fully structured interviews because they did not need to express the distance. In fact, a high level of attention was paid to the painting drawings. It is thought that students cannot rely on their drawing abilities because they cannot reflect the rotation relationship between the sun, earth, and moon in detail in three-dimensional thinking. It can also be said that not drawing during the lesson or drawing with teacher guidance is effective in this. Şenel and Çepni (2015) stated that such situations may be caused by the lack of knowledge of teachers. Bülbül et al. (2013) stated that this kind of incomplete or inaccurate information may be related to the daily life of students' perceptions about these concepts. It is known that students learn this information from the book and the teacher. It is also known that students do not reinforce this information in the museum, planetarium, or science centers. In general, it was determined that students could reflect a part of what they have learned in other measurement tools. Similar to these findings, Erbil and Kocabaş (2015) found that students could reflect what they have learned as a result of the activities carried out in the classroom. In his study, Adatepe (2018) determined that prospective teachers could reflect what they have learned in practice. In addition, Farrell (2007) stated in his study that reflecting is the demonstration of an individual's ability to think back and learn. It is assumed that students think about the information learned during drawing.

According to the findings of the survey about the sun, earth, and moon, the fact that the students had a 2.5 point average out of three indicates that they were at a very good level of knowledge. This data could be interpreted as students comprehended the information about the sun, earth, and moon. The mean score of the students who participated in the true-false tests was 12.61 and it was found to be good at $63.05 \%$. According to this, it can be said that students gave correct answers to more than half of the questions about the sun, earth, and moon. Similarly, Trumper (2003) and Kalkan and Kiroğlu (2007) used surveys to collect information. In general, it could be said that the students reflected their knowledge in the questionnaire items to $63.05 \%$ true-false tests. As a matter of fact, the survey items were arranged according to the textbook and the cases in the program and it was determined that the students achieved a very good score. When these items were transferred to the truefalse test and presented to the students, the result was found to be above average. In other words, the students transferred their knowledge to a similar level from the survey to true-false test. Furthermore, when the relationship between the meaning of these two test scores was questioned, the $\rho$ value was $>0.05$ and it was determined that there was no significant relationship between the scores. This finding shows that the students 
gave similar answers to the survey and the true-false test. Kaplan and Tekinarslan (2013) found a significant difference between the astronomy concepts of different group students in their experimental study. This study was not similar to those findings. In addition to these findings, students had incomplete or incorrect answers. The reason for this situation may be the lack of opportunity to examine the concepts in place or missing materials. In general, it could be said that some of the missing and incorrect information determined in the study was due to the pure knowledge accumulation or misinformation related to the students' daily life (Ogan-Bekiroglu, 2007). In addition, it was determined that the observations made about the astronomy concepts (with telescope, etc.) facilitated the correct learning of those concepts (Plummer, 2014; Trundle et al., 2007). In general, it was determined that students could reflect the information they learned on a different measurement tool. Similar to this finding, Phan (2007) found that different methods and techniques used in the classroom environment affected the students' knowledge. In addition, Demiralp and Kuzu (2012) suggested that teachers were positively affected when students used interactive educational environments to reflect their knowledge.

\section{CONCLUSIONS AND RECOMMENDATIONS}

It is determined that students knew the concepts of sun, earth, and moon and their properties. In addition, it had been determined that students had sufficient knowledge of the order of magnitude and the magnitude of the relationship between these three concepts and the relations and duration of the rotation. However, it was determined that the students did not provide any data for the distance between the sun, earth, and moon. It should be the aim of education to address and construct the relationships between these three concepts.

No problems were found in the three-dimensional thinking skills of the students about the size ratios and distance between the sun, earth, and moon. However, it was determined that the students had a very low relationship between the rotation of them and the data for all three dimensions. Students were required to structure the information in the light of visual data explaining the relationship between these concepts. In addition, these concepts should be encouraged to be displayed in a virtual environment and to show rotation relations. In general, it could be said that the students reflected their knowledge about the sun, earth, and moon to their three-dimensional ideas at an intermediate level.

As a result of the interpretation of the survey data, it was determined that the students had a very good level of knowledge about the sun, earth, and moon and that this information reflected in the true-false test of $63.05 \%$. To have a high reflection rate, it is necessary to review the usage situations in different situations in learning the information. In addition, there is no significant relationship between the survey scores and true-false test scores. This result shows that there was no difference between the determination of the information of the students with one measurement tool and another measurement tool.

In general, it was determined that students reflected their knowledge based on a fully structured interview form in the medium-level three-dimensional thinking skills measurement form. To increase this ratio, models, images, computer simulations or virtual materials should be used in the training of spatial concepts. Finally, it was determined that the students could reflect the knowledge of the survey with the true-false test. To measure the students' level of knowledge, a survey or true-false tests could be used. As a matter of fact, they both offer the same results.

\section{DISCLOSURE STATEMENT}

The authors declare that they have no conflicts of interest.

\section{FUNDING}

The research is not supported by any institution or organization.

\section{ETHICAL APPROVAL}

All procedures performed in studies involving human participants were in accordance with the ethical standards of the institutional and/or national research committee and with the 1964 Helsinki declaration and its later amendments or comparable ethical standards. For this reason, permission was obtained from the managers at the institution where the study was conducted. Voluntary participation was provided to the research.

\section{REFERENCES}

Adatepe, S. (2018). Examining Entrepreneurship Characteristics and Reflective Thinking Levels of Pre-service Teachers at Physical Education and Sports School. Unpublished Master Thesis, Bartin University Institute of Educational Sciences, Bartin, Turkey.

Arık, S., \& Yilmaz, M. (2017). Attitudes of science teachers towards environmental problems and their metaphorical perceptions for environmental pollution. Kastamonu Education Journal, 25(3), 1147-1164.

Ary, D., Jacobs, L.C., Irvine, C.K.S., \& Walker, D.A. (2019). Introduction to Research in Education. Mexico: Cengage.

Aydın, V. (2013). A Study on 3D-Virtual Reality in Science Education Programs: "Solar System and Beyond: Space Puzzle" Unit Sample. (Unpublished Master's Thesis, Adnan Menderes University, Institute of Social Sciences, Aydin).

Bektaşl1, B. (2013). The development of astronomy concept test for determining preservice science teachers' misconceptions about astronomy. Education and Science, 38(168), 362-372.

Bozdemir, H., Çevik, E.E., Altunoğlu, B., \& Kurnaz, M. (2017). The effects of different methods used in teaching astronomy subjects on academic success: A meta analysis study. Journal of Field Education Research, $3(1), 12-24$.

Bozkurt, E., \& Özdemir, İ.E.Y. (2018). A collaborative approach in professional development: Lesson study. Kastamonu Education Journal, 26(1), 109-116.

Bülbül, E., İyibil, Ü.G., \& Şahin, Ç. (2013). Determination of elementary school $8^{\text {th }}$ grade students' perceptions about the astronomy concept. Journal of Research in Education and Teaching, 2(3), 170-179.

Büyüköztürk, Ş. (2009). Manual of Data Analysis for Social Sciences. Ankara: Pegem Academy. 
Çakmak, Z., Konyalıoğlu, A.C., \& Işık, A. (2014). The investigation of pre-service elementary mathematics teachers' content knowledge on three dimensional objects. Middle Eastern and African Journal of Educational Research, 8, 28-44.

Çepni, S. (2010). Introduction to Research and Project Work. Trabzon: Celepler Printing.

Creswell, J.W. (2013). In: Whole, M., \& Demir, S.B. (Eds.), Qualitative Research Methods. Ankara: Political Publications Distribution.

Demiralp, D., \& Kuzu, H. (2012). Teachers' views on the contribution of primary education programs in developing reflective thinking of students. Pegem Education and Training Journal, 2(2), 29-38.

Demiralp, N. (2006). Map and sphere use skills in geography education. Turkish Journal of Educational Sciences, 4(3), 323-343.

Deniş, Ç.H., \& Balım, A. (2012). Effects of project based learning of the "solar system and beyond: Space puzzle" unit on student achievement. Journal of Theoretical Educational Science, 5(3), 254-277.

Diğler, M. (2018). Painting Education in Pre-school. Ankara: Pegam Academy.

Elaldı, Ş., \& Semerci, Ç. (2018). Reflection-in-learning scale: An adaptation to Turkish, validity and reliability study. Kastamonu Education Journal, 26(2), 369-378.

Erbil, D.G., \& Kocabas, A. (2015). Developing reflective thinking skills of primary school third grade students through cooperative learning. International Journal of Educational Programs and Teaching Studies, 5(9), 63-79.

Ersozlu, Z.N., \& Kazu, H. (2011). The effect of reflective thinking development activities on academic achievement in primary school fifth grade social studies lesson. Uludag University Faculty of Education Journal, 24(1), 141-159.

Falk, J.H., \& Dierking, L.D. (2018). Learning from Museums. New York: Rowman and Littlefield.

Farrell, T.S.C. (2007). Reflective Language Teaching. New York: Continuum.

Field. A. (2000). Discovering Statistics Using SPSS for Windows. London: Sage Publications.

Glesne, C. (2013). In: Ersoy, A., \& Yalcinoglu, P. (Eds.), Introduction to Qualitative Research. Ankara: ANI Publishing.

Gülen, S. (2019). Determination of Misconceptions of the Measuring Force and Friction Unit with their Reasons in $5^{\text {th }}$ Graders. $2^{\text {nd }}$ International Congress of Social Sciences, 30 January-02 February, Nevşehir, Turkey.

Gülen, S., \& Demirkuş, N. (2014).The effect of visual material on student success in the solar system and beyond: Space jigsaw unit. Yüzüncü $Y_{l} l$ University Journal of the Faculty of Education, 11(1), 1-19.

Kahraman, M.E. (2018). Basic design in an application course: Threedimensional design training. Journal of International Social Research, 11(56), 554-561.

Kalkan, H., \& Kiroğlu, K. (2007). Science and nonscience students' ideas about basic astronomy concepts in preservice training for elementary school teachers. The Astronomy Education Review, 1(6), 1-10.

Kaplan, G., \& Tekinarslan, İ.Ç. (2013). A Comparison of knowledge levels of students with and without intellectual disabilities about astronomy concepts. Elementary Online, 12(2), 614-627.

Kirındı, T., \& Ulu, M. (2017). Evaluation of science course curriculum according to the teacher views. Gazi Journal of Educational Science, $3(3), 55-71$.

Kiroğlu, K., Türk, C., \& Erdoğan, İ. (2019). Which one is more effective in teaching the phases of the moon and eclipses: Hands-on or computer simulation? Research in Science Education, 1-28. DOI: 10.1007/ s11165-018-9815-7. [Last accessed on $2020 \mathrm{Feb} 12]$.

Kizılkaya, G., \& Askar, P. (2009). Developing a reflective thinking skill scale for problem solving. Education and Science, 34(154), 82-93.

Kurnaz, M., Bozdemir, H., Altunoğlu, B., \& Çevik, E.E. (2016). Examination of national papers on astronomy subject in science education. Journal of Erzincan University Faculty of Education, 18(2), 1398-1417.

Lin, T.J., Lin, T.C., Potvin, P., \& Tsai, C.C. (2018). Research trends in science education from 2013 to 2017: A systematic content analysis of publications in selected journals. International Journal of Science Education, 41, 367-387.

Merriam, S.B. (2013). In: Turan, S. (Ed.), A Guide for Qualitative Research Design and Implementation. Ankara: Nobel Publishing.

Miles, B.M., \& Huberman, A.M. (1994). Qualitative Data Analysis. $2^{\text {nd }}$ ed. London: Sage Publication.

Ministry of National Education (MoNE). (2018). The Curriculum of Science Courses (Grades 3-8). Ankara: Ministry of Education Publications.

Ogan-Bekiroglu, F. (2007). Effects of model-based teaching on pre-service physics teachers' conceptions of the moon, moon phases, and other lunar phenomena. International Journal of Science Education, 29(5), 555-593.

Olkun, S., \& Altun, A. (2003). The relationship between elementary school students' computer experiences and spatial thinking and geometry achievements. The Turkish Online Journal of Educational Technology, 2(4), 86-91.

Özer, M. (2018). Strategic goals and new directions of measurement, Selection and placement Center. Journal of Higher Education and Science, 8(2), 221-226.

Phan, H. (2007). An examination of reflective thinking, learning approaches, and self-efficacy beliefs at the university of the south pacific: A path analysis approach. Educational Psychology, 27(6), 789-806.

Plummer, J.D. (2014). Spatial thinking as the dimension of progress in an astronomy learning progression. Studies in Science Education, 50(1), $1-45$.

Şahin, G. (2014). Pictures as a visual stimulus in preschool children's books. Turkish Studies International Periodical for the Languages, Literature and History of Turkish or Turkic, 9(3), 1309-1324.

Schermelleh-Engel, K., Moosbrugger, H., \& Müller, H. (2003). Evaluating the fit of structural equation models: Tests of significance and descriptive goodness-of-fit measures. Methods of Psychological Research Online, $8(2), 23-74$.

Şenel, Ç.T., \& Çepni, S. (2015). Teacher problems and misconceptions encountered in "solar system and beyond: Space jigsaw" unit: A special case study. Journal of Theoretical Educational Science, 8(2), 268-281.

Trumper, R. (2003). The need for change in elementary school teacher training a cross-college age study of future teachers' conceptions of basic astronomy concepts. Teaching and Teacher Education, 19(3), 309-323.

Trumper, R. (2010). A cross-age study of junior high school students' conceptions of basic astronomy concepts. International Journal of Science Education, 23(11), 1111-1123.

Trundle, K.C., Atwood, R.K., \& Christopher, J.E. (2007). Fourth-grade elementary students' conceptions of standards-based lunar concepts. International Journal of Science Education, 29(5), 595-616.

Türk, C., \& Kalkan, H. (2017). Student opinions on teaching astronomy with hands-on models. Journal of Human Sciences, 14(4), 3853-3865.

Türk, C., \& Kalkan, H. (2018). Teaching seasons with hands-on models: Model transformation. Research in Science and Technological Education, 36(3), 324-352.

Üstün, U., \& Ery1lmaz, A. (2014). A research method for effective research synthesis: Meta-analysis. Education and Science, 39(174), 1-32.

Yenilmez, K., \& Şan, İ. (2008). Level of recognition of visual models of identities of ninth grade students. e-Journal of New World Sciences Academy, 3(3), 409-418.

Yıldırım, A., \& Şimşek, H. (2013). Qualitative Research Methods in the Social Sciences. Ankara: Seçkin Publishing. 


\section{APPENDIXES}

Dear students, I would like to collect information about you from the sun, earth, and moon. This information will be used in a scientific study. It will not be graded. I'm just waiting for you to answer the questions asked to the extent you know. Participation is voluntary. Thank you...

\section{Appendix 1: Time to think}

1. Can you write all you know about the sun?

2. Can you write all you know about the moon?

3. Can you write down all you know about the earth?

4. In your opinion, what is the relationship between the sun, earth, and moon?

\section{Appendix 2: Picture time}

Dear students; I want you to think about the earth, the sun, and the moon, and draw a picture with you in mind the relationship between these three (pay attention to the size ratios, distance and geometric shapes of earth, and sun and moon in the picture you draw).

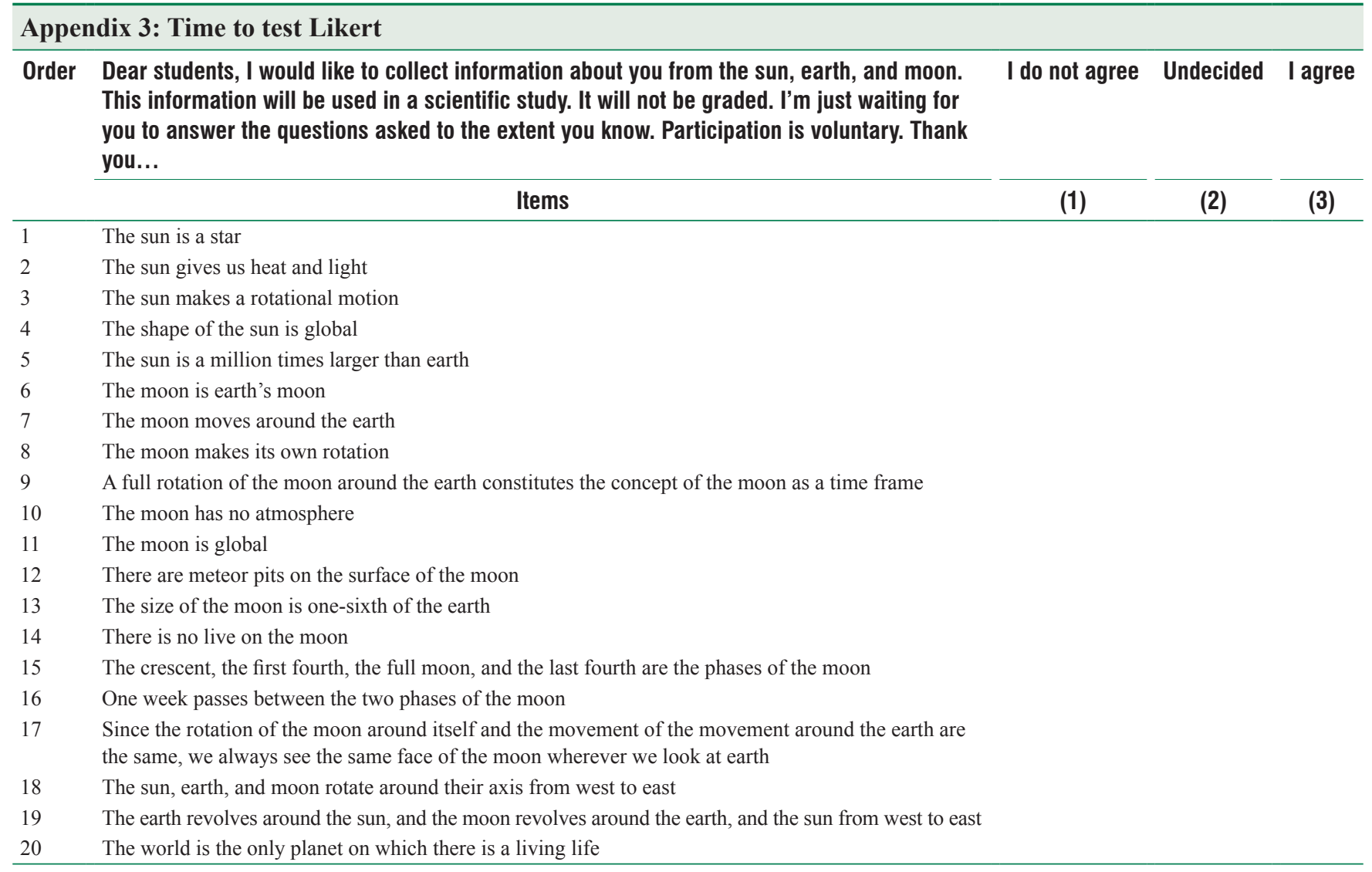




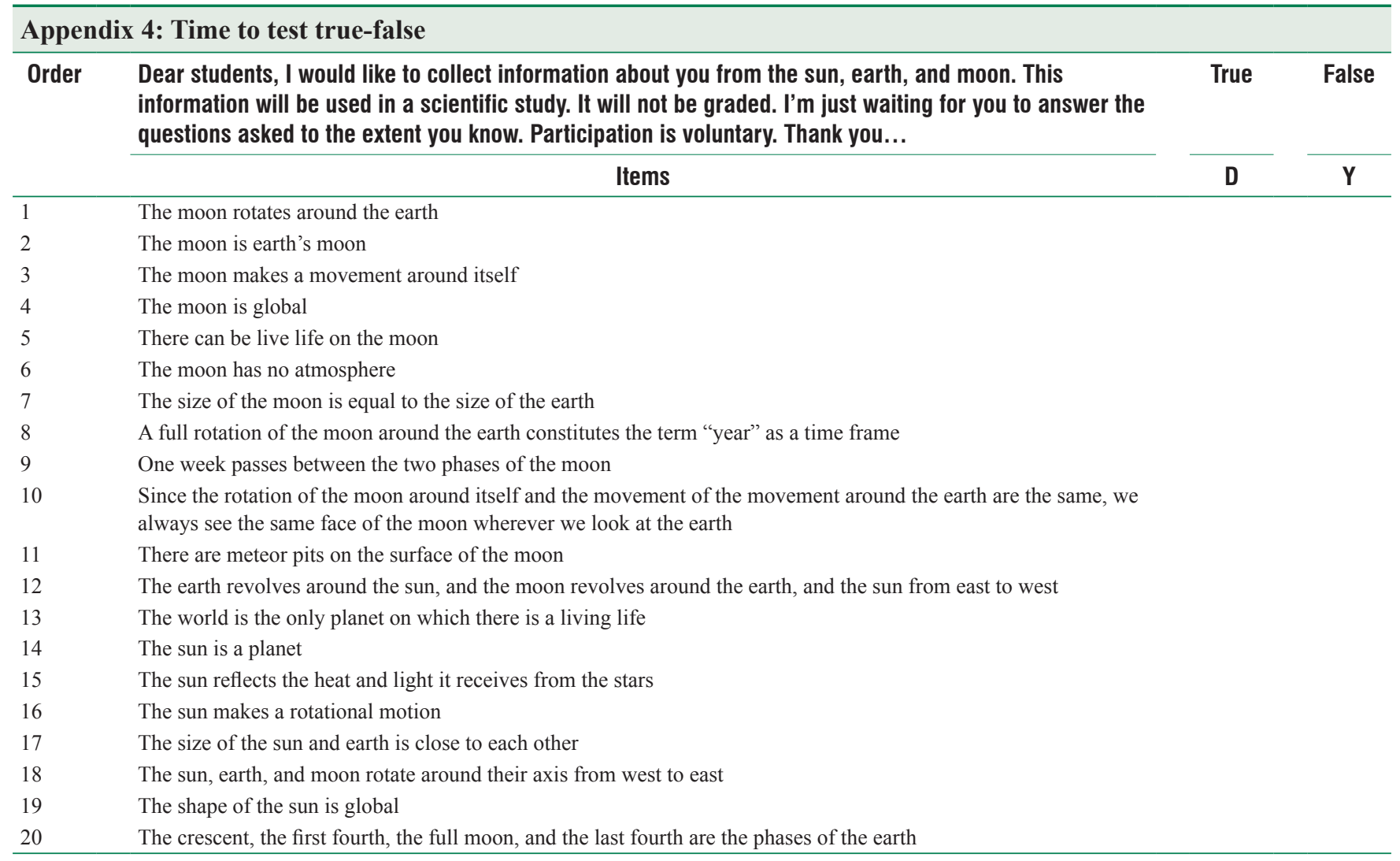

